\title{
OUTBREAKS OF INFECTIOUS BURSAL DISEASE IN VACCINATED AND UNVACCINATED COMMERCIAL COCKEREL FARMS IN BANGLADESH
}

\author{
M. T. Islam and M. A. Samad \\ Department of Medicine, Faculty of Veterinary Science, Bangladesh Agricultural University, Mymensingh - 2202, \\ Bangladesh
}

\begin{abstract}
ABSTRAC'T
Infectious bursal disease ( IBD) is a contagious viral disease has been reported in young broiler and layer chickens from Bangladesh. This communication report the outbreaks of IBD on two vaccinated (Gumboro D7 $8^{\circledR}$, Intervet ) and one unvaccinated commercial cockerel farms which were diagnosed on clinico-pathological findings and assessment of ELISA antibody titre. The outbreaks of IBD occurred on two vaccinated farms in cockerels of 29 to 31 days (Farm 1 ) and 30 to 33 days (Farm 2 ), whereas 19 to 22 days old in unvaccinated (Farm 3 ) birds. It caused $39.38 \%$ (Farm 1 ) and $75.0 \%$ (Farm 2 ) mortality in vaccinated and $29.20 \%$ ( Farm 3 ) in unvaccinated cockerel farms. Clinical investigation showed rapid onset, dullness, depression, anorexia, whitish loose diarrhoea, soiling and pasting of the vent, ruffled feathers, trembling and finally prostration and death due to dehydration. Necropsy examination revealed dehydrated carcasses, enlargement and oedematous swelling of bursa Fabricius and some cases yellowish, haemorrhagic, yellowish and caseous exudate in the bursa. Skeletal muscles especially thigh muscles showed haemorrhages in some birds. The IBD ELISA antibody titre of both the vaccinated and the unvaccinated moribund cockerels showed at vulnerable state and the mean antibody titre of vaccinated farm 1 had $161 \pm 59.22$ and vaccinated farm 2 had $57.82 \pm 14.85$, whereas unvaccinated farms had $194 \pm 90.35$. The occurrence of IBD outbreaks in both the vaccinated and unvaccinated birds indicate not only vaccination failure but also defective control strategies, which resulted heavy economic loss ( $85.05 \%)$ in the three cockerel farms. Therefore, a sound control strategy requires monitoring of maternal derived antibody with correct vaccination policy as well as good biosecurity principles to control IBD in Bangladesh.
\end{abstract}

Key words: Outbreaks, infectious bursal disease, cockerels, vaccination failure

\section{INTRODUCTION}

Poultry industry in Bangladesh has made significant progress during the last two decades and still it is considered as a growing industry. Poultry meat mainly comes from local fowls, broiler and cockerels in Bangladesh. Poultry farmers usually prefer to cockerel rearing due to low cost of day-old chicks, required less floor space and feed, cockerel-meat price is higher than the broiler meat. However, the major problem in the development of poultry industry in Bangladesh is the diseases, which causes high morbidity and mortality (Bhattacharjee et al., 1996 ; Samad and Chakraborty, 1993 ; Talha et al., 2001) but recently outbreaks of infectious bursal disease (IBD) has been recognized as a major constraint in the development of broiler and layer industry in Bangladesh (Chowdhury et al., 1996 ; Rahman et al., 1996 ). Review of literatures on poultry diseases reveal that so far only one report on management and disease problem of cockerels has been made from Bangladesh ( Sil et al., 2002.). This paper describes outbreaks of IBD in vaccinated and unvaccinated cockerels with its economic impact in Bangladesh.

\section{MATERIALS AND METHODS}

Reports of sudden mortality in cockerels were received from three commercial cockerel farms during the months of October and November 2002, from the Bhangnamari union of Gauripur upazilla, which are situated about 10 kilometer from the district town of Mymensingh. The detail investigation of these three outbreaks was carried out by visiting them intensively and by taking regular information from the owners of these farms. The management systems of these farms, clinical findings, date and age of outbreaks, and mortality were recorded. The detail informations of schedule vaccination in relation to mortality were noted for analysis. The dead and five moribund cockerels from each of the three farms were collected as soon as possible for necropsy of dead birds and blood collection from moribund birds. Swabs from heart and liver were collected for screening of the bacterial infections.

Sera were separated from the collected blood by conventional method and stored at $-20{ }^{\circ} \mathrm{C}$ until tested for ELISA antibody titre. Diagnosis of IBD was made on the basis of history, clinical signs and characteristic gross lesions on the bursa Fabricius and leg muscles and assessment of ELISA antibody titre. The sera were tested for IBD antibody titre by using commercial ELISA kit ( IDEXX Lab., USA). The detail informations about investment like price of day-old cockerel, feed cost and others, and the total income by sale of cockerels were noted from the owners for cost-benefit analysis. 


\section{RESULTS AND DISCUSSION}

The mortality pattern of cockerels due to infectious bursal disease ( IBD ) during outbreak in vaccinated and unvaccinated farms are presented in Table 1. The outbreak of the disease was first recorded in farm no. 1 on October 2, 2002 , and 28 days later the outbreak of IBD was detected in farm no. 2, whereas the outbreak of the disease was reported from third farm immediately after five days (November 5, 2002) of the onset of IBD at the second cockerel farm (Table 1 ). All these three cockerel farms were located in the same areas within a kilometer. On investigation it was found that the cockerels of farms no. 1 and 2 were vaccinated against IBD with commercial live Gumboro D78 ${ }^{\circledR}$ (Intervet ) and against Ranikhet disease with live BCRDV ( Bangladesh ) as per manufacturer instructions, whereas cockerels of farm no. 3 was only vaccinated against Ranikhet disease with BCRDV.

Table 1. Mortality pattern due to infectious bursal disease in vaccinated and unvaccinated cockerel farms

\begin{tabular}{|c|c|c|c|c|c|c|c|c|}
\hline \multicolumn{6}{|c|}{ Vaccinated against IBD } & \multicolumn{3}{|c|}{ Unvaccinated against IBD } \\
\hline 02.10 .02 & 29 & 050 & 30.10 .02 & 30 & 225 & 05.11 .02 & 19 & 042 \\
\hline $03,10.02$ & 30 & 075 & 31.10 .02 & 31 & 280 & 06.11 .02 & 20 & 090 \\
\hline 04.10 .03 & 31 & 190 & 02.11 .02 & 33 & 395 & 08.11 .02 & 22 & 160 \\
\hline Total & & $315(39.38 c$ & & & $900(75.0 \%)$ & & & $292(29.2 \%)$ \\
\hline
\end{tabular}

$\mathrm{n}=$ No. of cockerels

The mortality rate due to IBD in the two vaccinated cockerel farms ( No. $1 \& 2$ ) was found higher ( $39.38 \%$ and $75.0 \%$ ) in comparison to unvaccinated cockerels ( $29.2 \%$ ) of farm no. 3 ( Table 1 \& 2 ). However, the clinical outbreak of IBD was recorded in vaccinated flock at the age of 29 days in farm no. 1 and 30 days in farm no. 2 but it was appeared earlier at 19 days old in unvaccinated cockerels of farm no. 3 (Table 1 ). The course of the disease could not be determined in this study because owners dispose of all the birds due to high mortality. These observations are in conformity with the earlier report of Muhammad et al. (1996) who reported failure of vaccines to control IBD in broilers of 17 to 35 days old and in layer of up to 45 days old. It also supports the report of Sivaseelan and Balachandran (1999) who reported $20 \%$ mortality rate in vaccinated and $20 \%$ mortality in unvaccinated flocks and suggested that this could be due to lack of maternal antibodies in the unvaccinated flocks and failure of vaccine. The ELISA antibody titre of the vaccinated flock ( farm no. 1) varied from 89 to 250 with mean of $161 \pm 59.22$ ( SD ) and flock no. 2 varied from 32 to 69 with a mean of $57.82 \pm 14.85$, whereas unvaccinated flock it was varied from 87 to 309 with a mean of $194 \pm 0.35$ ( Table 2 ). It appears from these results that the mean ELISA titre is comparatively higher in unvaccinated birds ( $194 \pm 90.35$ ) than the vaccinated flock no.1 ( $161 \pm 59.22$ ) and flock no. 2 ( $57.82 \pm 14.85$ ). But the ELISA antibody titre of both the vaccinated and unvaccinated flocks are extremely low in comparison to the protective level of 1000 against natural infection of IBDV (Homer et al., 1992). It indicates that the vaccines might have neutralized the maternal antibodies in vaccinated flocks and the maternal antibodies of the unvaccinated flocks might be decreased at low level to resist the natural virulent infection. These findings indicate that vaccine is required to control IBD in cockerels but vaccination with milder vaccines will not be effective in birds with high levels of maternal antibody. Therefore, knowledge of maternal derived antibody levels and correct timing are necessary for successful vaccination to control IBD.

The onset of the disease was rapid and was characterized by dullness, depression, anorexia, and whitish loose diarrhoea, soiling and pasting of the vent, ruffled feathers and trembling. The moribund birds became prostrated and died due to severe dehydration. These cases did not respond to broad spectrum antibiotics. These clinical observation recorded in this study are in conformity with the earlier reports of Saha and Majumdar (1997) and Chauhan et al. (1980) who reported clinical signs of natural outbreak of IBD in chickens.

The dead birds presented dehydration of the subcutaneous tissues and muscles and inflamed vents. The petechial haemorrhages on the thigh and breast muscles were recorded in some birds. The most prominent lesion was enlargement and oedematous swelling of bursa Fabricius in early outbreaks, whereas in a small number of chicks minute streaks of petechial haemorrhages were also noticed on the inner surface of bursa. Some bursa became yellowish in colour, slimy to gelatinous material was noticed inside the bursa. Some changes like enlargement and changes in colour were also noticed on the liver, kidney and spleen. These post-mortem changes recorded in this study are in conformity with the earlier reports of Chauhan et al. (1980), Rajeswar and Mohan (1992), Saha and Majumdar 
Table 2. Relationship between the immunization and mortality due to infectious bursal disease in cockerel birds

\begin{tabular}{|c|c|c|c|c|c|c|c|c|c|}
\hline \multirow{2}{*}{$\begin{array}{l}\text { Farm } \\
\text { No. }\end{array}$} & \multirow{2}{*}{$\begin{array}{l}\text { Total No. } \\
\text { of birds }\end{array}$} & \multirow{2}{*}{$\begin{array}{l}\text { Source of birds } \\
\text { ( Hatchery) }\end{array}$} & \multicolumn{3}{|c|}{ Immunization status } & \multicolumn{2}{|l|}{ Mortality } & \multicolumn{2}{|c|}{ IBD ELISA titre } \\
\hline & & & Vaccines used & Age (days) & Route & Age (days) & No. (\%) & Range & Mean $\pm S D$ \\
\hline 1 & 800 & Kazi & $\begin{array}{l}\text { BCRDV }^{\circledast} \\
\text { Vibursa-CE }^{\otimes}\end{array}$ & $\begin{array}{l}4 \& 12 \\
22\end{array}$ & $\begin{array}{l}\mathrm{IO} \\
\mathrm{SC}\end{array}$ & $29-31$ & $315(39.38)$ & $89-250$ & $161 \pm 59.22$ \\
\hline 2 & 1200 & BRAC & $\begin{array}{l}\text { BCRDV }^{\circledR} \\
\text { Vibursa-CE }\end{array}$ & $\begin{array}{l}7 \\
15\end{array}$ & $\begin{array}{l}\mathrm{IO} \\
\mathrm{SC}\end{array}$ & $30-33$ & $900(75.0)$ & $32-69$ & $57.82 \pm 14.85$ \\
\hline 3 & 1000 & Kazi & ND Clone- $30^{\circ}$ & 7 & IO & $19-22$ & $292(29.20)$ & $87-309$ & $194 \pm 90.35$ \\
\hline
\end{tabular}

BCRDV $^{\circledR}=$ Baby Chick Ranikhet Disease Vaccine (Bangladesh), Vibursa-CE ${ }^{\circledR}=$ Infectious bursal disease vaccine (Vineland, USA), ND Clone- $30^{\oplus}=$ Newcastle disease vaccine (Intervet, The Netherlands), ELISA titre of moribund cockerels ( 5 birds / farm ) determined by the commercial ELISA kit ( IDEXX Lab., USA ).

(1997) and Sivaseelan and Balachandran (1999). However, Sivaseelan and Balachandran (1999) reported that the IBD affected bursa enlargement ( $75 \%$ ), haemorrhage ( $25 \%$ ), yellowish ( $60 \%$ ) and caseous exudate ( $40 \%$ ). Cosgrove (1962) reported that specific characteristic signs and lesions distinguished IBD as a specific cavity. Calnek et al. (1997) also opined that the lesions produced by IBD virus are pathognomonic. Hanson (1967) considered necropsy lesions as diagnostic and histopathological examination of bursa was rarely necessary for confirmation of IBD (Faragher, 1972).

The direct microscopic examination of the intestinal ( caecal ) content was found negative for parasitic ( coccidia ) infection and swabs collected from the heart blood also found negative for any bacteria of pathological significance. Thus, the IBD was diagnosed on the basis of history, clinical findings, pathognomic necropsy findings and extremely low level (unprotective) of ELISA antibody titre in moribund chicks.

The economic importance of the IBD is manifested in two ways, the first is due to the clinical disease and mortality in chickens and the sccond and more important, manifestation is a severe prolonged immunosuppression of chickens infected at an early age. Sequelae of the immunosuppression include secondary bacterial infection, and vaccination failure. However, an attempt was made to analyze economic losses due to only mortality caused by outbreaks of IBD in three cockerel farms ( Table 3 ). It appears from the Table 3 that a total of Taka 53,190/-was invested by the three cockerel farmers, and outbreaks of IBD associated with heavy mortality resulted a total loss of Taka 45.240/$(85.05 \%$ ) due to IBD ( Table 3 ). It may be concluded from this study that IBD is an important devastating endemic disease in Bangladesh which is occurred as outbreak form whether vaccinated or unvaccinated chicks accounting for severe economic losses in poultry industry.

Table 3. Economic impact of cockerel farming caused by outbreaks (mortality) due to infectious bursal disease

\begin{tabular}{|c|c|c|c|c|c|c|c|}
\hline \multirow{2}{*}{$\begin{array}{l}\text { Farm } \\
\text { No. }\end{array}$} & \multirow{2}{*}{$\begin{array}{l}\text { Total No. } \\
\text { of birds }\end{array}$} & \multicolumn{4}{|l|}{ Investment (Taka) } & \multirow{2}{*}{$\begin{array}{l}\text { Total } \\
\text { income* } \\
\text { (Taka) }\end{array}$} & \multirow{2}{*}{$\begin{array}{l}\text { Total +profit / } \\
\text {-loss (Taka ) }\end{array}$} \\
\hline & & $\begin{array}{l}\text { Total price of day- } \\
\text { old cockerels }\end{array}$ & Feed cost & Others ${ }^{\mathrm{U}}$ & Total & & \\
\hline 1 & 0800 & $3,600 /{ }^{4}$ & $07,400 /-$ & $1,540 /-$ & $12,540 /-$ & $2,910 /-$ & $-9,630 /$ \\
\hline 2. & 1200 & $8,400 /-^{b}$ & $14,675 /-$ & $2,000 \%$ & $25,075 /-$ & $1,500 /-$ & $-23,575 /-$ \\
\hline 3. & 1000 & $8,300 / \pi^{\circ}$ & $05,425 /$ & $1,850 \%$ & $15,575 /$ & $3,540 /-$ & $-12,035 /-$ \\
\hline Total & 3000 & $20,300 /-$ & $27,500 /$ & $3,390 /-$ & $53,190 /-$ & $7,950 \%$ & $-45,240 \%$ \\
\hline
\end{tabular}

"Taka 4/ chick and Taka 400/- as transport cost, 'Taka 7/chick (transport cost included), "Taka 8/chick and Taka 300/- as transport cost, ${ }^{d}$ Included vaccines, drugs, premix, litter. bulb etc. *Income from sale of birds.

\section{REFERENCES}

1. Bhattacharjee PS, Kundu RL, Biswas RK, Mazumder JU, Hossain E and Miah AH (1996). A retrospective analysis of chicken diseases diagnosed at the Central Disease Investigation Laboratory Dhaka. Bangladesh Veterinary Journal $30: 150$ - 153.

2. Calnek BW, Barnes HJ, Beard CW, McDougald LR and Saif YM (1997). Diseases of Poultry. 10 ${ }^{\text {th }}$ edn., Iowa State University Press, USA.

3. Chauhan HVS, Jha GJ, Singh MP and Thakur HN (1980). Outbreaks of infectious bursal disease (Gumboro disease) in poultry. Indian Journal of Poultry Science 15 : 253-258. 
4. Chowdhury EH, Islam MR, Das PM, Dewan ML and Khan MSR (1996). Acute infectious bursal disease of chickens : pathological observation and virus isolation. Asian-Australasian Journal of Animal Sciences $9: 465-469$.

5. Cosgrove AS (1962). An apparently new disease of chickens - avian nephrosis. Avian Diseases $6: 385$ - 389 .

6. Faragher JT (1972). Infectious bursal disease of chickens. Veterinary Bulletin $42: 361-369$.

7. Hanson BS (1967). Postmortem lesions diagnostic of certain poultry diseases. Veterinary Record $80: 109-122$.

8. Homer BL, Butcher GD, Miles RD and Rossi AF (1992). Subclinical infectious bursal disease in an integrated broiler production operation. Journal of Veterinary Diagnostic Investigation $4: 406-411$.

9. Muhammad K, Muneer A, Anwer MS and Yaqub MT (1996). Failure of vaccines to control infectious bursal disease in commercial poultry. Pakistan Veterinary Journal $16: 119-121$.

10. Rahman MM, Rahman MM, Islam AHMN, Miah AH, Mazumder JU and Bhattacharjee PS (1996). Observations on outbreaks and subsequent control of infectious bursal disease in the Central Poultry Farm in Bangladesh. Bangladesh Veterinary Journal $30: 13-17$.

11. Rajeswar JJ and Mohan CPC (1992). A report on the first incidence of infectious bursal disease among broiler chickens in Kanyakumari district of Tamil Nadu. Indian Veterinary Journal $69: 867-868$.

12. Saha AK and Majumdar AK (1997). Report of infectious bursal disease among grower chickens in Tripura. Indian Veterinary Journal $74: 515-516$.

13. Samad MA and Chakraborty SR (1993). Chemotherapeutic management of acute outbreaks of caecal coccidiosis in broiler birds in Bangladesh. Journal of Protozoology Research 3 : 140-143.

14. Sil GC, Das PM, Islam MR and Rahman MM (2002). Management and disease problems of cockerels in some farms of Mymensingh, Bangladesh. International Journal of Poultry Science 1 : $102-105$.

15. Sivaseelan S and Balachandran C (1999). A study on the pathology of infectious bursal disease under natural and experimental conditions. Indian Veterinary Journal $76: 599-602$.

16. Talha AFSM, Hossain MM, Chowdhury EH, Bari ASM, Islam MR and Das PM (2001). Poultry diseases occurring in Mymensingh district of Bangladesh. Bangladesh Veterinarian $18: 20-23$. 